\title{
When to Eat to Beat Obesity and Diabetes?
}

\section{Akbar Nikkhah*}

Department of Animal Sciences, Nanjing, University of Zanjan, Zanjan 313-45195, Iran

*Corresponding author: Akbar Nikkhah, Chief Highly Distinguished Professor, Department of Animal Sciences, Faculty of Agricultural Sciences, University of Zanjan, Zanjan 313-45195 Iran, Tel: 982415151; E-mail: nikkhah@znu.ac.ir

Received: June 06, 2014, Accepted: June 19, 2014, Published: June 27, 2014

Copyright: $\odot 2014$ Nikkhah A. This is an open-access article distributed under the terms of the Creative Commons Attribution License, which permits unrestricted use, distribution, and reproduction in any medium, provided the original author and source are credited.

\section{Editorial}

The existing nutrient intake recommendations and guidelines do not take ET effects on human metabolism and public health into account [1]. This editorial aims to establish serious global awareness on the effects of Eating Timing (ET) (morning and day vs. evening and night) on intermediary metabolism and metabolic diseases management. Time for practical understanding of chronophysiology and its contributions to sustaining quality life has arrived.

It has widely been revealed that human glucose intolerance by peripheral cells increases as day leaves for night. This is logical since human has evolved to rest overnight following the daylight-driven period of extensive nervous and metabolic activities. This evolutionary analysis founds a feasible global intake regimen to avoid or at the very least to minimize large evening meals to help prevent unhealthy visceral adiposity, central obesity, insulin resistance, diabetes mellitus, and cardiovascular disturbances. As far as night-workers are concerned, specialized dietary regimens with recommendations on 'when to eat which nutrient more or less' will need to be formulated $[2,3]$.

In generating the above roadmap in signifying the importance of 'when to eat or not to eat', human health science has partly been indebted to recent discoveries in animal physiology. Under thermoneutral conditions, evening feeding has considerably altered circadian rhythms of nutrient intake by increasing postfeeding rates of energy intake and in some scenarios by elevating the daily nutrient intake $[4,5]$. As a result, evening vs. morning feed provision increased rumen volume and metabolism as well as peripheral nutrient availability. In so doing, night eating has enhanced milk production and improved nutrient intake and gain efficiency in beef cattle [2]. Ruminants have evolved to graze mostly during day (especially around sunrise and sunset) and to rest and ruminate mainly overnight. Unlike in humans, nocturnal glucose intolerance and insulin resistance have not been conclusively reported in ruminants. Thus, in modern production systems, by increasing nutrient intake rate and amount, night instead of morning feeding may provide close-to-optimal ruminal, postruminal, and splanchnoperipheral conditions for nutrient assimilation, partitioning and utilization. But, in contrast, night eating would perturb normal human physiology and metabolism.

To conclude, evolution offers feasible-to-practice lessons among which is to manipulate ET to help optimize intake circadian patterns, nutrient metabolism, cell physiology, and public health. A most realistic and highly economical approach towards quality life in the new era will be to find out when to eat to beat obesity and diabetes.

\section{Acknowledgments}

The Iranian Ministry of Science, Research and Technology and University of Zanjan are thankfully acknowledged for supporting the author' global programs of optimizing science edification in the new millennium.

\section{References}

1. Dietary Reference Intakes (DRI) (2007) Recommended Intakes for Individuals, Food and Nutrition Board, Institute of Medicine, National Academies. National Academy of Sciences, Washington, D.C. USA.

2. Nikkhah A (2012) Time of Feeding an Evolutionary Science, Lap Lambert Publishing, GmbH \& Co. KG, Germany, ISBN 978-3-8473-3260-2.

3. Nikkhah A (2011) Science of eating time: A novel chronophysiological approach to optimize glucose-insulin dynamics and health. J Diabetes Mellitus 2: 8-11.

4. Nikkhah A (2013) Chronophysiology of ruminant feeding behavior and metabolism: an evolutionary review. Biol Rhythm Res 44: 197-218.

5. Nikkhah A (2011) Bioscience of ruminant intake evolution: feeding time models. Adv Biosci Biotechnol 2: 271-274. 